\title{
Prevalence and Associated Factors of Hypertension in Morocco: A Review
}

\author{
Abdeslam El Kardoudi , Kamal Kaoutar, Ahmed Chetoui , Fatiha Chigr , Mohamed Najimi
}

\begin{abstract}
HTA is a major public health problem worldwide. Indeed, previous studies have reported that $26.4 \%$ of the adult population was hypertensive, for an estimated total of 972 million people: 333 million in developed countries and 639 million in developing countries. For the year 2025, researchers estimated that $29.2 \%$ of the adult population will be hypertensive, which represents 1.56 billion individuals, leading by consequent to an increase of $60 \%$ in 25 years. In addition, the morbidity and the mortality caused by this disease is increasing in a remarkable way in the developing countries.

In Morocco hypertension prevalence data are very scare and limited, the national survey of the Ministry of Health conducted in 2000 , reveals a prevalence of $33.6 \%$; a rate that remains high as in other Maghreb or in Mediterranean countries.

With regard to the factors involved in this epidemiological situation, it is clear that the radical and irreversible change in lifestyle has contributed significantly to the increase in chronic disease rates, including hypertension. The other main factors could be summarized as: age, food, sedentary lifestyle. It should be noted that there is a almost absence of studies on the prevalence of hypertension and the associated factors in Morocco, which in itself is a limiting factor for understanding the etiology of hypertension. The prevalence of hypertension in Morocco remains high, investigations carried out in this context could improve scientific knowledge and thus, contribute to the prevention and control of the various factors associated with this disease.
\end{abstract}

The objective of this work is to summarize the published work, in relation with the prevalence of hypertension and associated factors in Morocco.

Index Terms - Associated factors, Blood hypertension, Morocco, prevalence.

\section{INTRODUCTION}

Hypertension is a major concern for public health systems in both developed and developing countries $[1 ; 2]$. It constitutes a major cause of death and morbidity in cardiovascular medicine. More than a quarter of the world's adult population is hypertensive [3], or one billion people

Abdeslam El Kardoudi ,Laboratory of Biological Engineering, Faculty of Science and Technology, Sultan Moulay Slimane University, Beni Mellal, Morocco

Kamal Kaoutar,Laboratory of Biological Engineering, Faculty of Science and Technology, Sultan Moulay Slimane University, Beni Mellal, Morocco

Ahmed Chetoui,Laboratory of Biological Engineering, Faculty of Science and Technology, Sultan Moulay Slimane University, Beni Mellal, Morocco

Fatiha Chigr , Laboratory of Biological Engineering, Faculty of Science and Technology, Sultan Moulay Slimane University, Beni Mellal, Morocco

Mohamed Najimi ,Laboratory of Biological Engineering, Faculty of Science and Technology, Sultan Moulay Slimane University, Beni Mellal, Morocco with high blood pressure. The hypertension burden weighs heavily on complications and health expenditures.

Morocco is a country experiencing a double transition, demographic and nutritional giving rise to a high prevalence of hypertension, maintained by economic, social, nutritional and environmental factors and which is accentuated in combination with communicable and infectious diseases [20].

The present work consists of the elaboration of a bibliographic review examining the work done on the prevalence of hypertension and related factors in Morocco.

\section{METHODS}

In this review, we have included reports, articles, abstracts and dissertations from doctoral theses in medicine. The results of the scientific work were downloaded from the following search engines (databases): PubMed, Google Scholar and Science Direct. The main keywords used in this research were: hypertension, associated factors, prevalence and Morocco. We prioritized the studies and the original works related to the hypertension, the data of these studies were analyzed and confronted to make sure of their relevance.

\section{CURRENT STATE OF KNOWLEDGE}

In Morocco, hypertension is one of the main reasons for consultation in outpatient health services. It constitutes the major cause of cardiovascular disease, which is one of the leading causes of morbidity, disability and death [15]. These diseases place a heavy burden on the individual, the community and the health system. Their cost of care in public health practice is very high [15]. Similarly, a very large number of hypertensives fail to achieve adequate control of their blood pressure; a national longitudinal study has revealed that more than half of hypertensive patients (52.5\%) had a high or extremely high cardiovascular risk, and that abdominal obesity was the most common cardiovascular risk factor (61.7\%) [39]. Almost all the articles included in this study consider hypertension as a major public health problem in both developed and emerging countries. The situation in Morocco is shared with the other Maghreb countries, Boukli Hacène and Meguenni (2007) indicate that Algeria is in an epidemiological transition phase revealed by the country's health statistics, and that the growing burden of no communicable diseases is threatening [10]. High rates of hypertension and poor care in countries in sub-Saharan-Africa have led to disastrous health complications such as stroke [7], 7.5 million deaths $(12.8 \%$ of deaths) [8]. In developed countries, the World Health 
Organization (WHO) reports hypertension as the leading cause of death, affecting more than one in three adults [32]. Epidemiological data show that hypertension is strongly associated with the occurrence of cardiovascular diseases [9]. Generally, hypertension leads to the reduction of the life span from 10 to 20 years [11].

\section{RESULTS}

The bibliographic analysis reveals the existence of 9 articles that refer to the prevalence of hypertension and associated factors in the Moroccan context. The prevalence rates selected for these different items vary between $33.6 \%$ and $55 \%$., Thus, according to the survey of the Ministry of Health in 2000, conducted on a representative sample of the Moroccan population aged 20 and over, and which aimed to identify the risk factors or protective factors of hypertension and the determination of the rate of its detection and treatment, the recorded rate was at $33.6 \%$. This rate is in the range of $38.6 \%$ in the Haouz region (Marrakech) according to a study that has was conducted among 451 people aged 20 and over residing in the Azguour Valley (Amizmiz circle, Tahanawt province, wilaya of Marrakech). However, the study of a sample of 306 subjects aged 65 years and over in the province of Safi, which aimed to determine the prevalence of cardiovascular risk factors in this population, recorded a prevalence of order of 55\%. The lowest prevalence rate was recorded in the provinces of Khemissat and El Jadida $(16.7 \%)$ [40].

The risk factors identified in the various studies are: smoking, unhealthy diet, excessive salt intake, sedentary lifestyle, overweight, obesity, age and hereditary factor.

\section{DISCUSSION}

\section{A. Characteristics of data published in selected articles}

According to the criteria we have selected, only 9 articles have dealt with this issue of hypertension in Morocco. However, the Ministry of Health survey conducted in 2000 was the only one which addressed the prevalence and factors associated with hypertension. Five other studies reported the prevalence of cardiovascular risk factors in Marrakech, Safi in Meknes, Oujda, Khemissat and El Jadida. It should be noted that two studies were devoted to the study of the diabetes and hypertension association on the one hand, and obesity and hypertension on the other hand, in the eastern region of Morocco. The last national longitudinal survey selected in this literature review included 909 hypertensive patients. It has aimed to determine the proportion of patients with controlled hypertension and to describe the cardiovascular risk profile in hypertensive patients in Morocco.

Although it is the only source that has specifically dealt with hypertension, the national prevalence survey shows two limitations: the lack of completeness of the data, or even the absence of relevant details in the subject and the age of the data.

The studies carried out in the aforementioned Moroccan cities can not claim to be a relevant source either, since hypertension has not been treated as a separate pathology but as a factor associated with other diseases such as diabetes and obesity. In addition, these studies are specific and geographically limited and reflecting a lifestyle different from other Moroccan regions.

\section{B. Prevalence of hypertension}

The epidemiological situation of hypertension in Morocco shows that it is a serious problem of public health. The reviewed studies show a high prevalence of hypertension. A survey conducted in 2000 nationwide showed that $33.6 \%$ of Moroccans aged 20 and over are hypertensive [1]. The highest value was recorded in the region of El Haouz (38.6\%) according to the study conducted by Zaki and Aboussaad (2004). The prevalence of hypertension increases significantly with age; it is $53.8 \%$ among people over 40 years of age and $72.2 \%$ among those aged 65 and over [33]. In the province of Safi, it reaches $55 \%$ among the population aged 65 and over [27]. Another study of the general population of the city of Khemissat and El Jadida, which involved a sample of 10524 subjects, reported a prevalence of hypertension of $16.7 \%$ [40].

Compared with the Maghreb countries, there is a noticeable difference between the prevalence recorded in Morocco and those of other countries, especially the neighboring countries. According to a WHO report on the global situation of no communicable diseases in 2010, the prevalence of hypertension in this region is $45.8 \%$ in Libya, $40 \%$ in Egypt and $38 \%$ in Tunisia [25]. In Algeria, the prevalence found is of the order of $35.3 \%$ according to a survey carried out at the national level [36].

At the Mediterranean level, the prevalence recorded in Morocco is much lower than that recorded in Spain $42.6 \%$ (49.9\% for men and $37.1 \%$ for women) [35], in Portugal, which reaches $54,7 \%$ for men and $41.1 \%$ for women aged 35 to 64 [37] and in Italy (34\%) [34]. In France, approximately 7 million patients are treated for hypertension, and it has been estimated that several million unmanaged hypertensives [12], the prevalence reported in this country is almost similar to that of Morocco, it is around 34.8\% [24].

At the continental level, it is clear that the difference between national prevalence and that of sub-Saharan countries remains significant, since hypertension affects $28 \%$ of the sub-Saharan population [3]. Indeed, the rates of hypertensives aged 20 and over respectively reach $15.1 \%, 23.9 \%, 27.50 \%$, $28 \%$ and $31.1 \%$, in Cameroon, South Africa, Senegal, in Zimbabwe and Tanzania [20].

It appears from the comparisons made previously, that the prevalence of hypertension in Morocco is close to that of neighboring countries, it becomes lower in going up north and higher in relation to the country of the south. In general, the prevalence of hypertension is higher in the northern countries which are more developed with a Westernized way of life (quality and quantity of industrialized foods, low level of physical activity, stressful lifestyle), unlike the southern country.

\section{Factors associated with hypertension}

The analysis of the different studies dealing with hypertension in the Moroccan context, shows that age, gender, local eating habits (excessive consumption of salt) and lifestyle (sedentary lifestyle, smoking and alcohol), as well as the hereditary factor [6] remain the main risk factors. With regard to the age factor, the prevalence of hypertension in Morocco was respectively $19.2 \%$ [1], 30\% [1], 51.1\% [1], $63.3 \%$ [1] et $71 \%$ [1] in the age groups of 20 to 34 years, 35 
to 44 years, 45 à 54 years, 55 à 64 years and 65 and over Thus, it appears that the increase in blood pressure and the risk of cardiovascular mortality are predominant in the elderly [1] in agreement with previous studies in other countries $[2 ; 8 ; 20$; $21 ; 23 ; 25 ; 26 ; 35 ; 36]$.

The analysis of these data also shows that HTA affects women much more than men, (37\% vs. $30.6 \%)$ [1], (41\% vs. $35.8 \%)$ in Safi [16] and (21.9\% against $15.4 \%)$ in Marrakech [27]. In Oujda, a study conducted on 624 women of childbearing age, non-pregnant, with no known pathology found that the most represented cardiovascular risk factors are abdominal obesity $(79.1 \%)$ and hypertension (35\%) [38].The results of the work carried out in Morocco relating the age and sex factors, are in agreement with the data obtained in the Mediterranean carrier and at the continental level. In Algeria, the HTA gains more ground in the age group of 55 to 70 years, with a predominance of women $(20 \%$ for men and $28.5 \%$ for women) [2;19] However, other studies report a prevalence of $49.7 \%$ in women and $51.3 \%$ in men [17;18]. In Tunisia and Lebanon, 36\% of women are hypertensive against $25 \%$ of men in Tunisia [25] and $35.4 \%$ against $27.3 \%$ in Lebanon [26].

In France, the frequency of hypertension is at level of $33 \%$ in males and $37 \%$ in females. In the general population, it reaches $61 \%$ for men and $74 \%$ for women aged from 65 to 74 years old [23]. With respect to age, the risk of being hypertensive is 11 times higher in the age group 55 to 64 years and 25 times higher in the age group 65 years and older $[13 ; 24]$.

Studies in sub-Saharan Africa report identical results [3], with $70 \%$ of people aged 50 and over suffering from hypertension, its prevalence increasing to $65 \%$ among older respondents aged 65 and over $[20 ; 21]$.

With regard to data relating socio-economic and cultural status, dietary and toxic habits (alcohol, tobacco) and lifestyle habits are almost absent to our knowledge. However, in developing countries factors related to the place of residence and the socio-economic affect significantly the prevalence. There is some unequal distribution between the South and the North and between rural and urban areas [22]. In France, for example, the prevalence is higher in Lille and Strasbourg than in Toulouse, and is very prevalent in the north compared to the south [24]. Indeed, urbanization caused by the proportional, increases the prevalence of hypertension in areas called traditional or rural, the difference between the two environments illustrates the negative impact of urbanization on the determinants of risk cardiovascular in general and hypertension in particular [3].

For socioeconomic characteristics, the rate of hypertension is higher among illiterate or low-educated people. In people who are generally active, the prevalence does not exceed $7 \%$ [22]. The percentage of hypertensives is lower for executives and people in higher intellectual occupations (10\%). The income bracket is a determining factor that is important for the prevalence of hypertension, and is more important for people with limited income. On the marital status side, widows and married or divorced persons are more affected by this pathology [22]. In the same vein, Laid et al (2005) add that the unschooled and the unprofessional are also the most exposed to develop an arterial hypertension [2], except for the Lebanese women whose education level is not associated with the occurrence of hypertension [26].
In general, a change in the prevalence of hypertension according to socio-economic level was raised, so the lower the socio-economic level is, the higher the prevalence of hypertension exists. Merle et al (2009) and Elasmi (2009) reported that people with a lower socio-economic level are three times more likely to have hypertension according to studies in Tunisia and France [13;25].

The relationship observed between smoking and hypertension is very significant; smokers are twice as likely to develop hypertension as non-smokers or former smokers [22]. In addition, 55\% of hypertension cases are most often caused by non-compliance with dietary and lifestyle measures. The risk of hypertension is decreased among physical activity practitioners by 30 to 60 minutes of walking a day. The risk of hypertension also falls for those who consume fish and fruit at most once a week [1]. Thus, physical activity and adherence to the Lebanese Mediterranean diet was associated with lower blood pressure [26]. In the sub-saharan region, a significant association with unadulterated salt intake and estrogen intake and high hypertension was reported [21].

Diabetes and obesity are two risk factors that are strongly associated with hypertension. Thus, $55 \%$ of a population of diabetics hospitalized at the University Hospital Center of Oujda, are hypertensive, moreover macro-angiopathic complications are identified in $45 \%$ of these hypertensives [29]. According to another survey conducted in the same region, hypertension was associated with obesity in $50 \%$ of cases [30].

Studies in Western countries confirm the previously cited findings, and concluded that hypertensives are people with the following characteristics: abdominal obesity [22], diabetes [18], and reduced physical activity [13]. The most incriminated factor in the occurrence of hypertension is the body mass index (BMI): obese subjects are three times more likely to develop hypertension [3] than subjects with normal BMI [23], this index persists as the only contributing factor to hypertension in both sexes [26].

\section{CONCLUSION}

High blood pressure is a disease that is gaining ground in Morocco; it is a major risk factor for cardiovascular diseases that disrupts the well-being of the Moroccan population.

The results from the various studies conducted in the Moroccan context, even if they are rare, are very alarming, revealing a very high prevalence, a low rate of detection of control and treatment.

The study of the risk factors of hypertension in the Moroccan citizen shows that this risk increases steadily with age in both sexes and is higher in rural areas and among diabetics. Only the introduction of a healthy lifestyle can affect cardiovascular risk factors in general and hypertension in particular, this way of doing will certainly have positive effects on the well-being of the population.

In the light of this literature review, it appears that several avenues of research can be pursued in the Moroccan context, we cite the study of the association between nutritional and epidemiological transition and the prevalence of hypertension, comparative studies of the prevalence of hypertension between age groups and between environments, with emphasis on the different characteristics of each environment and age group, the study of associations between 
hypertension and the various factors associated (diabetes vs. hypertension, obesity vs hypertension ...). It would be relevant to look at the lifestyle of hypertensive people and its association with blood pressure control or the contribution of this lifestyle in the occurrence of hypertension or in increasing its prevalence.

\section{CONTRIBUTION OF THE AUTHORS}

Abdeslam El KARDOUDI, Kamal KAOUTAR and Ahmed CHETOUI contributed to the bibliographic research and the writing of the article.

Mohamed NAJIMI and Fatiha CHIGR supervised and corrected the article.

This study has been funded by PPR type B program (Pr M. Najimi).

\section{REFERENCES}

[1] S. Abir-khali, F. Lahmouz, ML. Arrach, N. Chaouki, "Facteurs de risque de l'HTA chez la population marocaine adulte," Revue de santé méditerranéenne, vol 15, no 4, 2009, pp. 827-841.

[2] Y. Laid, M. Atek, P. Traissac, "Hypertension et facteurs associés chez les adultes algériens 35-70ans," Revue d'Epidémiologie et de Santé Publique, vol.61, $\mathrm{n}^{\circ}$ S4, 2013, p. 286.

[3] L. Fourcade, P. Paule, B. Mafart, "Hypertension artérielle en Afrique subsaharienne actualité et perspectives," Revue générale Med Trop., vol.6, 2007, pp.559-567.

[4] M. Lebel, "Situation de l'HTA dans le monde et position du canada". Revue de la société canadienne de l'HTA, bulletin no.88 ,2006, pp. 1-8

[5] Organisation Mondiale de la Santé (OMS), " Rapport sur la situation mondiales des maladies non transmissibles « Atteindre les neuves cibles mondiales : une responsabilité partagée," OMS, 2014.

[6] Organisation Mondiale de la Santé (OMS), "Hypertension artérielle : un problème de santé publique, "Centre des médias. Événements et campagnes, Journées mondiales de la Santé précédentes OMS. 2013. http://www.emro.who.int/fr/media/world-health-day/public-health-pro blem-factsheet-2013.html.

[7] A. Niakara, L V A. Nebie, N M. Zagre and al, "Connaissances d'une population urbaine sur l'HTA : enquête prospective menée à Ouaguadouguou Burkina Faso," Bull Soc Pathol Exot, vol.96, no.3, 2003, pp. 219-222.

[8] LA. Bortolotto, O. Henry, O. Hanon, P. Sikias, X. Girerd, “ Faisabilité et intérêts de l'automesure chez le sujet âgé de plus de 75 ans," Arch Mal Cour Vaiss, vol.92, 1999, pp.1159-1162.

[9] G. Lefevre, E. Puymirat, "Hypertension artérielle et maladie coronaire : nouveau concept ?" Annales de Cardiologie et d'Angéiologie, vol.66, no.1,2017, pp.42-47.

[10] L. Boukli Hacene, K. Meguenni, "Facteurs de risque cardio-vasculaire dans la communauté urbaine de Tlemcen (Algérie) ", Cahiers Santé, vol. 17, no.3, 2007, pp.153-158.

[11] F. Pillon, J. Buxeraud, "L'essentiel de l'HTA", Actualités pharmaceutiques, no. 532, 2014, pp. 20-24.

[12] B. Baudin, EB. Garcias, C. Meuleman and al, "Biologie de l'hypertension artérielle", Revue francophone des laboratoires, no. 409, 2009, pp.65-74.

[13] S. Merle, K. Pierre-Louis, J. Rosine, T. Cardoso, J. Inamo, J. Deloumeaux, " Prévalence de l'hypertension artérielle en population générale à la Martinique," Revue d'Epidémiologie et de Sante Publique, vol.57, 2009, pp.17-23.

[14] Organisation Mondiale de la Santé (OMS), "Rapport sur la situation mondiale des maladies non transmissibles" OMS, 2010.

[15] Ministère de la Santé, "Enquête Nationale sur la Population et la Santé Familiale (ENPSF 2011). Projet PAPFAM”, Ligue des États Arabes, Le Caire, Egypte. Rabat, Maroc : Ministère de la Santé. December 2012. www.sante.gov.ma

[16] I. Zaki, A. Aboussaad, "La prévalence des facteurs de risque cardiovasculaires chez une population montagnarde du haut atlas marocain, " Thèse de doctorat en médecine. Faculté de médecine et de pharmacie de Marrakech. Maroc, 2010, pp. 1-159.

[17] F. Hamida. M-L. Atif, M. Temmar, A. Chibane, A. Bezzouacha, M-T. Bouafia, " Prévalence de l'hypertension artérielle dans l'oasis d'El-Menia, Algérie et profil métabolique de la population," Annales de cardiologie et d'angéiologie, 62, 2013, pp.172-178.
[18] N. Zanoun, S. Fraga, N. Dekkar, "L'hypertension artérielle dans la commune de Bab el oued : Prévalence, traitement et contrôle Algérie,' Santé-MAG, vol n63 2017, pp.2-5.

[19] AY. Berrouiguet, M. Benyoucef, K. Meguenni and al, "Enquête sur la prévalence des facteurs de risque des maladies cardiovasculaires à Tlemcen (Algérie),"Médecine des Maladies Métaboliques, vol.3, no.3, 2009, pp.313-319.

[20] E. Marcia, P. Duboz, L. Gueye, "L’HTA à Dakar / prévalence connaissance, traitement et contrôle," Bull. Soc. Pathol. Exot, vol 108, 2015, pp.49-56.

[21] K. Yahed, F. Damorou, R. Akakpo, T. Tcherou, N.W. N'Da, S Pessinaba, L. Belle, A. Johnson, "Prévalence de l'HTA et description de ses facteurs de risque à Lomé (TOGO), résultats d'un dépistage réalisé dans la population générale en mai 2011," Annales de cardiologie et d'angeiologie, vol.62, 2013, pp.43-50.

[22] L. Frérot, P. Le Fur, A. Le Pape, C. Sermet, "L'HTA en France prévalence et PEC thérapeutique," CREDES centre de recherche d'études et de documentation en économie de santé, Rapport d'enquête no.484, 1999, pp.15-20.

[23] A. Atallah, M. Kelly-Irving, J. Inamo, N. Zouini, J B. Ruidavets, T. Lang, "Prévalence de l'hypertension artérielle en Guadeloupe: l'enquête CONSANT," Revue d'épidémiologie et de santé publique, vol. 06, 2008, pp. 154-158.

[24] A. Wagner, D. Arveiler, J-B. Ruidavets, D. Cottel, V. Bongard, J. Dallongeville, J. Ferrières, P. Amouyel, B. Haas, "Etat des lieux sur l'hypertension artérielle en France en 2007 : l'étude Mona Lisa," BEH thématique, vol.9, no.50, 2008, pp.483-486.

[25] M. Elasmi, A. Mebazaa, M. Feki, H. Sanhaji, R. Jemaa, S. Haj Taeib, S. Omar, J. El Ati, M. Hsairi, M. Kaabachi, "Prévalence des facteurs de risque cardiovasculaires conventionnels dans la population du grand Tunis", Revue d'épidemiologie et de santé publique, vol. 57, 2009, pp. 87-92.

[26] M. Cherfan, J. Blacher, R. Asmar, and al, "Prevalence and risk factors of hypertension: A nationwide cross- sectional study in Lebanon," $J$ Clin Hypertens.; 00: 2018, pp.1-13. https://doi.org/10.1111/jch.13268

[27] H. EL Ghouizi, L. Essaadouni, "Prévalence des facteurs de risque cardiovasculaire chez les sujets âgés dans la province de Safi”, Thèse de doctorat en médecine. Faculté de médecine et de pharmacie de Marrakech. Maroc, 2011, pp. 1-134.

[28] K. Ben Mohammed, MT. Nguyen, N. Nouri, S. Khensal, J. Pariès, P. Valensi, A. Lezzar, "Prévalence de l'HTA chez les adolescents algériens. Rôle de l'excèdent pondéral et de l'insulinorésistance,' Diabetes \& amp ; Metabolism, Vol.36, no.1, 2010, p.44.

[29] H. Aynaou, H. Latrech, "Comorbidité cardiovasculaire chez le patient diabétique type 2 hypertendu," Annales d'Endocrinologie, vol.75, no.5-6, 2014, p.376.

[30] S. El Bakkay, A. Bour, "Prévalence des facteurs de risque de maladies cardiovasculaires chez la femme à Oujda (Maroc) ", Médecine des maladies Métaboliques, vol. 10 no.1, 2016, pp. 63-69.

[31] F. El Boukhrissi, Y. Bamou, H. Ouleghzal, S. Safi, L. Balouch, "Prévalence des facteurs de risque des maladies cardiovasculaires et du syndrome métabolique chez les femmes de la région de Meknès", Médecine des Maladies Métaboliques, vol 11, no.2, 2017, pp.188-194.

[32] Organisation mondiale de la santé (OMS), "Journée mondiale de la Santé. Alimentation, nutrition et hypertension," OMS, 2013, pp.1-7. www.emro.who.int/.../journee-mondiale-de-la-sante-2013/nutrition-hy pertension-facts...

[33] Ministère de la sante au Maroc, " Recommandations des bonnes pratiques médicales, l'hypertension artérielle de l'adulte”. Ministère de la santé, Maroc. 2012, pp. 1-85.

[34] P. Verdecchia, F. Angel, "The Seventh Report of the Joint National Committee on the Prevention, Detection, Evaluation, and Treatment of High Blood Pressure: The Weapons Are Ready". Rev Esp Cardiol, vol.56, no.9, 2003, pp. 843-847.

[35] E. Menendez, E. Delgado, F. Fernandez-Vega, M. Prieto, E. Bordiu, A. Calle, and al, "Prevalence, Diagnosis, Treatment and Control of Hypertension in Spain. Results of the Di@bet.es Study “, Rev Esp Cardiol, vol. 69, no. 6, 2016, pp. 572-578.

[36] A Y. Berrouiguet, K. Meguenni, M. Benyoucef, B. Faivre, M. Brouri, "Dépistage des facteurs de risque des maladies cardiovasculaire à Tlemcen," Diabetes \&amp ; Metabolism, vol.35, no.12009, pp.42-43.

[37] ME. Macedo, MJ. Lima, A. Oliveira Silva, P. Alcantara, V. Ramalhi nho, J Carmona, "Prevalence, awareness, treatment and control of hypertension in Portugal: the PAP study", Rev Port Cardiol, vol. 26, no.1, 2007, pp:21-39.

[38] S. El Bakkay, A. Bour, "Prévalence des facteurs de risque de maladies cardiovasculaires chez la femme à Oujda (Maroc)," Médecine des maladies Métaboliques, vol.10, no. 1, 2016, pp. 63-69. 
[39] M. Alami, M. El Hattaoui, M. Seqat, J. Sadik, A. Aouad, M. Benghanem Gharbi, "Control of blood pressure and cardiovascular risk in Moroccan patients with newly diagnosed hypertension: a 3-month observational study in primary care," Therapeutic Advances in Cardiovascular Disease, vol.11, no.2, 2017, pp. 49-56.

[40] M. Benghanem Gharbi, M. Elseviers, M. Zamd, A. Belghiti Alaoui, N. Benahadi, E Trabelssi, R. Bayahia, B. Ramdani, M E. De Broe, "Chronic kidney disease, hypertension, diabetes, and obesity in the adult population of Morocco: how to avoid "over"- and "under"diagnosis of CKD”, Kidney International, 2016, pp.1-9. 